\title{
An Innovated Possessor Suffix and Category in Central Choiseul
}

\author{
Bill Palmer
}

\author{
UNIVERSITY OF NEWCASTLE
}

\begin{abstract}
Oceanic languages typically display possessor-indexing suffixes that distinguish the usual four Oceanic person categories, along with at least singular and plural. However, a group of languages of central Choiseul (Solomon Islands), including Ririo, Babatana, and Sisiqa, display only three possessor-indexing suffixes. Two reflect Proto-Oceanic forms and index 1SG and 2SG possessors. The third, an innovated form, indexes all other person number categories (that is, 3SG and all nonsingular categories). This paper investigates the formal and structural characteristics of this innovated non-1/2SG suffix. It examines the phenomenon in each of the three languages, including allomorphy of the suffix, and the manner in which person and number categories are expressed in the presence of the innovated suffix. In terms of the former, it finds each language displays different allomorphy patterns, with both $-e$ and $-a$ occurring, along with $-i$ when following a high vowel. Various other factors are at play in one or more languages, including vowel harmony and presuffix vowel loss. In terms of the coding of non-1/2SG person and number categories, the paper finds that the innovated suffix licenses a possessor NP that may contain a lexical noun or dependent pronoun. However, in the absence of an overt possessor NP, the suffix prompts a default 3 SG reading.
\end{abstract}

1. INTRODUCTION. ${ }^{1}$ Oceanic languages typically display a direct possessive construction in which a set of suffixes attach to a possessum noun to index the person and number of the possessor, and an indirect construction in which the same set of suffixes attach to a possessive classifier. These suffixes typically distinguish the usual four Oceanic person categories 1st exclusive, 1st inclusive, 2nd, and 3rd, along with at least singular and plural (Lynch, Ross, and Crowley 2002:35-36). This means that they typically display separate suffixes distinguishing 3SG and each of the person categories in plural. This "standard average Oceanic" system is a direct reflex of the system reconstructed for ProtoOceanic (POC) (Ross 1988:112; Lynch, Ross, and Crowley 2002:67-68,75-76). However, a group of languages spoken in central Choiseul in the Solomon Islands displays an innovated possessor category and suffix expressing it that indexes all possessors other than 1SG and 2SG in the direct construction. This innovated suffix expresses 3SG and all nonsingular categories, with a separate dependent pronoun or lexical NP further specify-

1. I am grateful to Stephen Logan, John Lynch, and Malcolm Ross for comments on this paper. Any errors remain mine. 
ing the identity of the possessor. This paper provides an account of this innovated category and suffix in three central Choiseul languages: Babatana, Sisiqa, and Ririo. ${ }^{2}$

The west Choiseul languages Varisi and Vaghua display a set of singular possessorindexing suffixes that regularly reflect POC forms, as does the communalect Avasö, located at the southeastern tip of the island. As table 1 shows, these include a dedicated 3SG.PSSR form -na. The communalects of central and eastern Choiseul (excepting Avasö), however, display an innovated suffix appearing as $-a$ or $-e$ that occurs with 3SG possessors, but also occurs with possessors of all person/number combinations other than 1SG and 2SG. This will be referred to here as a non-1/2SG possessor suffix, or N1/2SG.PSSR. Data in Tryon and Hackman (1983:295) show this occurring in Babatana, Ririo, and communalects they identify as Tunöe and Lömaumbi, and apparently also Katazi. Ross (2002:458) shows Sisiqa displaying the same innovated form. On the basis of their lexicostatistical comparison, Tryon and Hackman (1983:451) identify Babatana, Sisiqa (as Sengga), Tunöe, and Katazi as dialects of a single language they call Central-East Choiseul (1983:32). Ross (1988:216-17) also treats these as dialects of a language he calls East Choiseul, but he includes Avasö in this grouping, although he does not give an explanation for this revision of Tryon and Hackman's classification. In subsequent work, Ross (2002:456) concludes that Sisiqa is sufficiently distinct from Babatana to warrant being regarded as a separate language.

The innovated N1/2SG.PSSR form under discussion here is, therefore, found in a grouping that will be referred to here as "central Choiseul," an areal grouping comprising the languages Ririo, Babatana, and Sisiqa, along with the communalects Tunöe, Lömaumbi, and Katazi. No claim about the internal phylogenetic structure of the Choiseul subgroup is intended by this, and no claims are made here about the dialect status of Tunöe, Lömaumbi, and Katazi with respect to each other or the other varieties. No data are available for Tunöe, Lömaumbi, and Katazi other than what is presented by Tryon and Hackman, so the discussion here is confined to an investigation of the $\mathrm{N} 1 / 2$ SG.PSSR suffix in Babatana, Sisiqa, and Ririo.

\section{THE INNOVATED SUFFIX IN INDIRECT POSSESSION. Oceanic} languages typically display an indirect possessive construction in which a separate form referring to the possessor precedes the noun. In the "standard average Oceanic" system,

\section{TABLE 1. CHOISEUL SINGULAR POSSESSOR-INDEXING SUFFIXES REGULARLY REFLECTING POC ${ }^{\dagger}$}

\begin{tabular}{|c|c|c|c|}
\hline POC & $\begin{array}{c}1 \\
*_{\text {-gu }}\end{array}$ & $\begin{array}{c}2 \\
*-m u\end{array}$ & $\begin{array}{c}3 \\
\text { *-ña }\end{array}$ \\
\hline Varisi & $-\mathrm{gu}$ & $-m u$ & -na \\
\hline Vaghua & -gə & $-m u$ & -na \\
\hline Avasö & $-g u$ & $-\mathrm{mu}$ & -na \\
\hline
\end{tabular}

2. Choiseul represents a first-order subgroup of Northwest Solomonic, itself a subgroup of Meso-Melanesian, a first-order subgroup of Western Oceanic (Ross 1988:215-17). 
the indirect possessive form is a relational classifier (Lichtenberk 1983) that distinguishes at least consumed (CONSPOSS) and general (GENPOSS) alienable possession, and carries the same suffixes found in the direct construction, distinguishing the same four person categories and at least two number categories (Lynch, Ross, and Crowley 2002:77-79). This construction occurs in all three languages under discussion here. However, only Babatana has retained a distinction between general and consumed possession. In Sisiqa and Ririo, that distinction has been neutralized and a single paradigm of indirect possessor forms occurs in each language. In all three languages, possessorindexing forms specific to the indirect construction occur only with singular possessors, shown in table 2. Plural possessors are expressed by dependent pronouns, following the pattern described for Babatana in section 3 below. Of the three languages, the innovated suffix occurs in indirect possession only in Babatana. The Sisiqa 3SG form displays the only relic of the POC 3SG.PSSR suffix attested in any of the three languages (with the possible exception of the 3SG reflexive form in Ririo; see note 12 below). The Ririo 3SG form displays neither a reflex of the POC suffix nor the innovated suffix. Details of the innovated suffix in the Babatana indirect construction are discussed further in section 3.

3. BABATANA. ${ }^{3}$ Possession in Babatana employs a set of suffixes that index the person and number of the possessor. However, only three categories of person and number are distinguished: $1 \mathrm{SG}(-q u), 2 \mathrm{SG}(-m u)$, and all other categories $(-e)$, as in (1). These occur in both the direct and indirect possessive construction. In the direct construction, for non-1/2SG categories, dual and plural possessors are expressed by a dependent pronoun (2) or NP possessor (5)-(6) licensed by the non-1/2SG suffix. In the absence of a dependent pronoun or NP possessor, the non-1/2SG suffix has a default 3SG reading, as in (1c), (3b), (7b), (9), and various other examples below. ${ }^{5}$

\section{TABLE 2. CENTRAL CHOISEUL SINGULAR INDIRECT POSSESSOR-INDEXING FORMS}

$\begin{array}{lccc} & 1 \mathrm{SG} & 2 \mathrm{SG} & 3 \mathrm{sG} \\ \text { Babatana GENPOSS } & \text { na-qu } & \text { na-mu } & \text { na-e } \\ \text { Babatana CONSPOSS } & \mathrm{a}-\mathrm{qu} & \mathrm{a}-\mathrm{mu} & \mathrm{a}-\mathrm{e} \\ \text { Sisiqa } & \text { qo } & \text { mo } & \text { ona } \\ \text { Ririo }^{\dagger} & \text { nòq } & \text { nòm } & \text { nèm } \\ & (/ \text { na-uq/) } & (/ \text { na-um/) } & (/ \mathrm{na}-\mathrm{im} / \mathrm{or} / \mathrm{na}-\mathrm{em} /)\end{array}$

$\dagger \quad$ The parenthesized Ririo forms are underlying forms inferred from the surface forms, on the basis of the principles of vowel coalescences discussed in section 5 .

3. Babatana data are from Money (2002) and McClatchey (2007), both largely representing Babatana as spoken in the area around Sasamuqa village.

4. Henceforth, forms are represented in the orthography used by the sources, with comment where necessary.

5. Babatana orthographic vowels have the corresponding IPA values, except $/ \mathrm{\partial} /=\ddot{o}, / \mathbf{i} /=\ddot{u}$, and $/ \mathrm{a} /=a$. (Whaley 1962:62 described the low vowel as being low back unrounded, that is, /a/, although he himself uses IPA /a/ as the symbol. Stephen Logan in a personal communication suggests it may, in fact, be a low central vowel.) Orthographic $j$ is a voiced alveopalatal affricate (roughly/dz/) (Whaley 1962:61). As elsewhere in the Western Solomon Islands, $q=/ \mathrm{g} /$ and $g=/ \mathrm{\gamma} /$. Money (2002) uses $\underline{n}$ for $/ \mathrm{g} /$, but $\eta$ is used here following McClatchey (2007). 

(1) a. puda-qu
bone-1SG.PSSR
bone-2SG.PSSR
'your bone'
b. puda-mu
c. puda-e
bone-N1/2SG.PSSR
'my bone'
'his/her bone'
(2) a. puda-e maru
bone-N1/2SG.PSSR 1EXCL.DU
b. puda-e dira
bone-N1/2SG.PSSR 3PL
'our (excl. dual) bone'
'their bone'

Dependent pronoun possessors such as those in (2) are referred to by Money (2002:30) as suffixes attaching to the 3SG suffix. However, they are treated here as prosodically separate syntactically dependent pronouns - syntactic clitics in Anderson's (2005) terms - because they occur elsewhere with various other functions, such as preposed indirect possessor forms and postverbal subject forms, and because they can be separated from the possessum noun by an adnominal modifier, as in (3c), or modify conjoined Ns, as in (4).
(3) a. tina-mu lata
mother-2SG.PSSR be.big
'your aunt'
mother-N1/2SG.PSSR be.big
'his/her aunt'
b. tina-e
c. tina-e lata dira
mother-N1/2SG.PSSR be.big 3PL
'their aunt'
(4) tama-e na tina-e diru
father-N1/2SG.PSSR and mother-N1/2SG.PSSR 3DU
'their mother and father'

The N1/2SG suffix has the underlying form/e/, which occurs following nonhigh vowels other than /e/, as in (2) and (5).
(5)
a. tatazo-e
mola
stern-N1/2SG.PSSR canoe
'the stern of the canoe'
c. tama-e sua iati
father-N1/2SG.PSSR child this
'this child's father'
b. sökö-e qolu want-N1/2SG.PSSR gold 'the wish for gold'

Following high vowels, the suffix retains its front feature, but undergoes height assimilation to $/ \mathrm{i} /$, as in (6). Where the root-final vowel is also $/ \mathrm{i}$ /, one of the resulting sequence of identical vowels then deletes, as in (7b) and (8).
$\begin{array}{ll}\text { (6) a. kuqu-i } & \text { pade } \\ \text { wall-N1/2sG.PSSR } & \text { house }\end{array}$
b. küdü-i vuru across-N1/2SG.PSSR river 'the other side of the river' 'the walls of the house'
(7) a. körisi-qu arm-1SG.PSSR
b. körisi arm.N1/2SG.PSSR 'his/her arm' 'my arm'
(8) körisi-i $\rightarrow$ körisi

Following /e/, the suffix appears as the allomorph - $a$, as in (9). 
(9) kekere-a

tooth-N1/2SG.PSSR

'his/her tooth'

The overwhelming majority of attested forms follow the regular pattern outlined above, in which the suffix simply concatenates with the final vowel of the root with no changes to the root. However, about a dozen attested roots follow this pattern but display an additional dimension: ${ }^{6}$ loss of the root-final vowel accompanied by vowel harmony of the vowel of the preceding syllable if that vowel is unstressed. ${ }^{7} \operatorname{In}(10)$, the final vowel has been replaced by the suffix $-e$. However, loss of the final vowel occurs after height assimilation of the suffix, as the suffix surfaces as /i/ when the elided final vowel is high, as in (12). As the roots in (10) are disyllabic, the syllable preceding the suffix after rootfinal vowel elision is stressed and, therefore, does not undergo assimilation (with the two exceptions in [14]-[16] discussed below). However, with trisyllabic roots, the syllable preceding the suffix after root-final vowel elision is unstressed. The vowel of that syllable undergoes total assimilation to the vowel of the suffix, as in (11) and (12). This occurs following suffix height assimilation and root-final vowel elision, as the assimilated vowel shares the height feature of the suffix, as in (12). If root-final vowel elision occurred before suffix height assimilation, the suffix in (12) would not undergo height assimilation to $/ \mathrm{i} /$, and the surface form would be *kuken-e. In other words, with this small group of roots: (a) the suffix concatenates, then undergoes height assimilation in the usual way; then (b) the root-final vowel deletes; then (c) the preceding unstressed vowel undergoes total assimilation, as in (13).

(10)
a. zito-qu
nose-1SG.PSSR
'my nose'
c. mata-qu
eye-1SG.PSSR
'my eye'
e. nöle-qu
chin-1SG.PSSR
'my chin'
b. zit-e
nose-N1/2SG.PSSR
'his/her nose'
d. mat-e
eye-N1/2SG.PSSR
'his/her eye'
f. nöl-e
chin-N1/2SG.PSSR
'his/her chin'
b. ziten-e
name-N1/2SG.PSSR
'his/her name'
(11) a. zitono-qu
name-1SG.PSSR
'my name'

6. No semantic or phonological pattern has been detected that distinguishes these roots from roots displaying the regular pattern. For example, roots referring to body parts and kin terms occur with both patterns.

7. Stress in Babatana appears to involve left-aligned trochaic feet. That is, the initial syllable carries stress (for example, /'vutini/ 'know'), unless a subsequent syllable has a long vowel and is, therefore, heavy (/'tuna/ 'nod head' vs. /tu'naa/ 'be true'). (Note that vowel length is not represented in the orthography and is, therefore, not represented elsewhere in this paper.) Reduplicants and the causative marker do not participate in stress: /va-'kula/ 'make happy', / qi 'qisu/ 'burden, load' ('RD carry'). Vowel harmony of an unstressed vowel here means in effect that the penultimate vowel of roots of more than one syllable undergoes harmony. 

c. talaya-qu
ear-1SG.PSSR
'my ear'
(12)
a. kukunu-qu
neck-1SG.PSSR
'my neck'
d. taley-e
ear-N1/2SG.PSSR
'his/her ear'
b. kukin-i
neck-N1/2SG.PSSR
'his/her neck'
(13) kukunu-e $\rightarrow$ kukunu-i $\rightarrow$ kukun-i $\rightarrow$ kukin-i

A further process of assimilation is attested with two disyllabic roots where a stressed vowel preceding the suffix is /u/. In this context, the high back vowel assimilates on the feature BACK to the value [-BACK], without also assimilating to the feature FRONT, resulting in the high central vowel / 1 /, as in (14) and (15). While this process is attested with only two roots, butu 'head' as in (14) and the otherwise slightly irregular $t u(t)$ 'child' (16), these do constitute 100 percent of the relevant context: attested roots in which a stressed vowel $/ \mathrm{u} /$ is in the syllable adjacent to the suffix. However, this process applies only to the high back vowel and not all back vowels, as it does not apply to the mid back vowel /o/, which occurs in several examples without losing the feature [+back], as in (17).
a. butu-qu head-1SG.PSSR 'my head'
(14)
b. butu-mu head-2SG.PSSR 'your head'
c. büt-i
head-N1/2SG.PSSR
'his/her head'
(15) butu-e $\rightarrow$ butu-i $\rightarrow$ but-i $\rightarrow$ büt-i
(16) a. tu-qu
child-1SG.PSSR
'my child'
a. jopa-qu
mouth-1SG.PSSR
'my mouth'
b. tu-mu
child-2SG.PSSR
'your child'
c. tüt-i
child-N1/2SG.PSSR
'his/her child'

The allomorph - $i$ may be readily explained as well-motivated height assimilation. However, the relationship between the allomorphs $-e$ and $-a$ is less immediately obvious. Two hypotheses are possible. In the first, the suffix is underlyingly /a/, but undergoes height assimilation in all contexts except following /e/, where the underlying form is retained to disambiguate the presence of the suffix. However, there are two problems with this hypothesis. First, there is no explanation for why the vowel always raises to a front vowel, rather than a mid or back vowel. Whaley (1962:62) analyzes Babatana $a$ as a low back vowel, in which case it would be expected to raise to /o/ and /u/. However, even if it is actually a low central vowel, which may, in fact, be the case (Stephen Logan, pers. comm.), the language has mid and high central vowels $/ \partial /$ and $/ \mathbf{i} /$ to which the vowel could raise. More fatally for this hypothesis, there is no explanation for why the suffix surfaces as /e/ following root-final /a/. The allomorph would be motivated by disambiguation of the suffix from the final vowel of the root, although this is not sufficient to motivate a disambiguating allomorph with root-final /i/, as in (7). However, there is no synchronic explanation for why the disambiguating allomorph is /e/ rather than some other vowel: clearly assimilation is not at play, so the allomorph must 
be lexical. A possible diachronic explanation would require the suffix to have originally had the form /e/, later shifting to /a/, with the original /e/ retained as a lexical allomorph after /a/, alongside the separately motivated height-assimilating allomorph /e/. This hypothesis would be consistent with (but not in itself evidence for) an originating form *e.

The alternative hypothesis is that the suffix is synchronically underlyingly /e/, accounting for raising to front $/ \mathrm{i} /$. In this hypothesis, the allomorph $/ \mathrm{a} /$ is a disambiguating allomorph following root-final/e/. This again must be a lexical allomorph, as /a/ is not directly motivated. However, disambiguating vowel-lowering from/e/ would necessarily result in /a/, as this is the only low vowel in the language (Whaley 1962:62), while disambiguating raising from /a/ under hypothesis 1 would not necessarily result in /e/. An alternative historical explanation would involve an original form $/ \mathrm{a} /$, which subsequently raised to /e/, with the original underlying form retained as an allomorph in the disambiguating environment following /e/.

Both hypotheses appear to involve a lexical allomorph with a disambiguating function, although phonological lowering in the second hypothesis would result in the observed vowel, while phonological raising in the first hypotheses would not (lowering from $/ \mathrm{e} /$ would necessarily result in $/ \mathrm{a}$, while raising from $/ \mathrm{a} /$ would not necessarily result in /e/). However, the first hypothesis does not account for why the underlying /a/ would raise to front vowels, while the second hypothesis does account for why /e/ would raise to /i/. For this reason the second hypothesis is assumed here: the underlying form of the suffix is /e/. This, in turn, is consistent with an originating form *a, or an originating form *e if disambiguating lowering occurred.

The Babatana indirect construction involves a somewhat different pattern. As is typical for Oceanic, the indirect construction involves a form that precedes the noun and refers to the possessor. In the "standard average Oceanic" system, the indirect possessive form is a relational classifier (Lichtenberk 1983) that distinguishes at least consumed and general alienable possession, and carries the same suffixes found in the direct construction, distinguishing the same four person categories and at least two number categories (Lynch, Ross, and Crowley 2002:77-79). Alone among the three languages under discussion here, Babatana formally distinguishes consumed and general possession in this construction. However, Babatana indirect possession differs from the typical Oceanic pattern in that the general possessive classifier $n a$ - occurs only with singular possessors, as in (18a-d). Nonsingular possessors are expressed by a dependent pronoun in prenominal position in place of the classifier, as in (18e). ${ }^{8}$
a. na-qu
pade GENPOSS-1SG.PSSR house 'my house'
c. na-e
pade
GENPOSS-N1/2SG.PSSR house 'his house'
b. na-mu
GENPOSS-2SG.PSSR house 'your house'
d. na-e
pade balava GENPOSS-N1/2SG.PSSR house old.woman 'the old woman's house'

8. The presence of dependent pronouns in this construction is consistent with Palmer and Brown's (2007) hypothesis that, in the indirect construction in some Oceanic languages, the classifier position is a syntactic head. However, further discussion of that is beyond the scope of the present work. 


\section{e. dira pade \\ 3PL house \\ 'their house'}

The Babatana consumed possessive classifier $a$-also occurs with singular suffixes, as in $(19 \mathrm{a}-\mathrm{c})$, but in this case does also occur with the nonsingular dependent pronoun to express the consumed possessive relation, as in (19d).

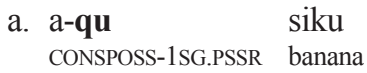
'my banana'
c. a-e peta ni gaki
CONSPOSS-N $1 / 2$ SG.PSSR thing ASSOC eat
'his food'
d. a-dira kuate
CONSPOSS-3PL fish
'their (DU) fish'

For the purposes of the present discussion, the significant fact is that the suffix - $e$ occurs in indirect possession but is confined to indexing $3 \mathrm{SG}$ possessors. Two hypotheses may account for its restriction to 3SG. In one hypothesis, the Babatana suffix - $e$ always expresses non- $1 / 2 \mathrm{SG}$, and has the default $3 \mathrm{SG}$ interpretation seen in the direct construction. The place of the dependent pronouns for nonsingular possessors in the indirect construction means that the suffix does not occur in that construction with categories other than 3SG, so the default interpretation is always invoked in this construction. This hypothesis has the advantage that the suffix has a consistent meaning across all occurrences, with other aspects of one of the constructions in which it occurs accounting for the restriction of meaning in that construction. The second hypothesis is that the suffix indexes $3 \mathrm{SG}$ in one construction, and $\mathrm{N} 1 / 2 \mathrm{SG}$ in another. This hypothesis has the disadvantage that it involves unmotivated polysemy in the suffix, in contrast with a motivated restricted interpretation of a semantically unitary suffix of the first hypothesis. For this reason, the first hypothesis is assumed here. The fact that Babatana alone displays the innovated suffix in the indirect construction, while Sisiqa retains a relic of the original 3SG.PSSR suffix, together suggest that the use of the innovated suffix in the indirect construction in Babatana is an extension of its use in the direct construction, that extension occurring after the separation of Babatana from Sisiqa and Ririo.

In summary, regular possessor-indexing in Babatana involves a suffix $-e$, which indexes non- $1 / 2 \mathrm{SG}$ possessors. In the indirect construction, the presence of nonsingular dependent pronouns in the classifier position prompts a default 3SG interpretation. The suffix undergoes raising assimilation following high vowels, with one vowel of a resulting sequence/ii/ deleting, and with the disambiguating lexical allomorph $-a$ following /e/. A limited pattern exists in which the root-final vowel deletes before the suffix after raising assimilation, leading to total assimilation of the vowel of the preceding syllable if unstressed. 
4. SISIQA. ${ }^{9}$ Sisiqa also displays N1/2SG.PSSR allomorphs $-e$ and $-a$. However, here the underlying form is /a/, with/e/ a lexical allomorph confined to the single environment of following /a/ (Ross 2002:458).

As with Babatana, Sisiqa direct possession distinguishes the possessor categories 1SG, $2 \mathrm{SG}$, and non-1/2SG, with person/number categories other than $1 / 2 \mathrm{SG}$ specified by means of a dependent pronoun or NP licensed by the suffix, as in (20). As in Babatana, the N1/2SG.PSSR suffix without an overt possessor pronoun or NP has a default 3SG reading, as in (21)-(25). ${ }^{10}$

$$
\begin{array}{ll}
\text { a. mata-e döra } & \\
\text { eye-N1/2SG.PSSR } & 3 \mathrm{PL} \\
\text { 'their eyes'; cf. (10d) }
\end{array}
$$
b. tama-e so göti father-N1/2SG.PSSR child DEM 'this child's father' (Ross 2002:460)

In Sisiqa, the underlying form of the suffix is $-a$, as demonstrated by the fact that this form surfaces following all vowels other than /a/, including /i/ (21), /u/ (22), /e/ (23), and /o/ (24). Following /a/, however, the lexical allomorph -e occurs to disambiguate the presence of the suffix, as in (20) and (25). The Sisiqa system is considerably less complex than that in Babatana. The suffix undergoes no height assimilation (21)-(24); there is no class of roots that undergo final-vowel loss before the suffix (22b,c), (23b), (24), (25b); and no root vowel assimilation takes place $(22 b, c),(24 b),(25 b)$. Sisiqa can, therefore, be regarded in this respect as more conservative than Babatana.

(21) körisi-a

arm-N1/2SG.PSSR

'his/her arm'; cf. (7)

(22)
a. bötu-qu
head-1SG.PSSR
'my head'; cf. (14a)
b. bötu-a
head-N1/2SG.PSSR
'his/her head'; cf. (14c)
c. kokunu-a
neck-N1/2SG.PSSR
'his/her neck'; cf. (12b)

(23)
a. kökere-a
tooth-N1/2SG.PSSR
'his/her tooth'; cf. (9)

b. yöle-a

chin-N1/2SG.PSSR

'his/her chin'; cf. (10f)

(24)
a. zejo-a
nose-N1/2SG.PSSR
'his/her nose'; cf. (10b)

b. taritono-a

name-N1/2SG.PSSR

(25)
a. pöda-e
bone-N1/2SG.PSSR
'his/her bone'; cf. (1c)

'his/her name'; cf. (11b)

With a synchronic underlying form /a/, there is no phonological motivation for disambiguating raising to /e/ after /a/, rather than to any other vowel. This, then, is consistent

9. Sisiqa data are from Ross (n.d.) unless otherwise stated.

10. Sisiqa orthography resembles that for Babatana, except that no $\ddot{u}$ occurs. Ross (2002:456) treats $\ddot{o}$ as a mid central vowel surfacing variably as [ə], [i], and [ø]. In Ross (n.d.), he transcribes it as $/ \mathbf{i} /$. 
with an originating form *e, retained as an allomorph with a disambiguating function when the suffix as a whole shifted to $/ \mathrm{a}$.

In summary, the Sisiqa N1/2SG.PSSR suffix involves straightforward concatenation of the suffix to the root, with the underlying suffix form $-a$ alternating with $-e$ following $/ \mathrm{a}$.

5. RIRIO. As with Babatana and Sisiqa, Ririo displays a N1/2SG.PSSR suffix -e. An allomorph - $a$ occurs in one specific context.

Ririo poses problems for analysis arising from its highly moribund status. At the time fieldwork was carried out on the language by Don Laycock in 1978, he reported 18 speakers, all of whom used Babatana as their normal daily language, and whose children and other family members spoke only Babatana. More recent fieldwork carried out in 2011 by Stephen Logan found only one native speaker and several rememberers. The language has also undergone borrowing from Babatana. Together, these facts make some of the Ririo data somewhat difficult to interpret. However, the basic facts are apparent from the available material. ${ }^{11}$

Ririo contains one possible relic of the original 3SG.PSSR suffix *-ña, in the 3SG reflexive pronoun tiò-n..$^{12}$ Aside from this single possible relic, direct possession in Ririo resembles Babatana and Sisiqa in distinguishing 1SG, 2SG, and non-1/2SG, with person/ number categories other than $1 / 2 \mathrm{SG}$ specified by a dependent pronoun or NP licensed by the suffix-e, as in (26). Again, the absence of an NP or dependent pronoun prompts a default 3SG.PSSR reading, as in (28c) and (29c), although occurrence with the 3SG independent pronoun is also possible, as in $(26 \mathrm{c}) .^{13}$

11. The Ririo data here are from Hackman (1967), Craven (1977), Laycock (1978, 1982), and Logan (fieldnotes). I am grateful to Stephen Logan for providing his field materials.

12. The Ririo reflexive paradigm contains dedicated reflexive forms for the singular categories: $t i o-q$ $1 \mathrm{SG}$, tiò- $m$ 2SG, tiò- $n$ 3SG. Nonsingular reflexives are formed using the general oblique preposition ta followed by the relevant dependent pronoun, for example, ta dor LOC 1INCL.DU 'our(two)selves'. The reflexive pronouns in Babatana do not also show a relic of *-na. Instead, they are formed regularly in all person/number categories except 3SG with direct possessor suffixes on the reflexive pronoun or preposition tana-; for example, tana-qu 'myself', tana=duru 'our(two)selves', etc. In 3SG, an irregular form is used in which a suffix $-i$ replaces the final vowel of the reflexive base, as tan-i or tan-ito. The reflexive paradigm for Sisiqa is not known.

An alternative explanation for Ririo tiò- $n$ is possible, in which the final $/ \mathrm{n} /$ does not reflect the suffix *-na. Instead, a reflexive root *tiana (resembling Babatana tana) undergoes metathesis, with subsequent raising of the metathesized $/ \mathrm{a} / \mathrm{to} / \mathrm{o} /(\grave{o})$, independently attested when /ava/ metathesizes (see note 15 below). This would give a derivation of the root as follows: *tiana $\rightarrow$ $*$ tiaan $\rightarrow *$ tian $\rightarrow *$ tion. However, this explanation may be rejected, as $/ \mathrm{a} /$ to $/ \mathrm{J} /$ in the attested context /ava/ presumably involves rounding arising from the labial feature of the $/ \mathrm{v} /$, a situation not applying to $/ \mathrm{n} /$, and because the expected resulting possessor-indexed forms would be *tion-uq and *tion-e.

13. Ririo orthography closely resembles that of Sisiqa. Again, $\ddot{o}$ represents a mid central vowel; except for Ririo it has been analyzed as representing variably /ø/ and /œ/ (Laycock 1982:273). Laycock represents $/ \mathfrak{y} /$ orthographically as ñ. However, as this conventionally represents a palatal nasal, not a velar, $\eta$ has been used here for clarity. Ririo also has a glottal stop, represented here, as conventionally, by an apostrophe. The glottal is a root-final allophone of $/ \mathrm{k} /$ where that consonant has been brought into final position through metathesis (Laycock 1982:275). Unlike Babatana and Sisiqa, Ririo has front and back low mid vowels $/ \varepsilon /$ and $/ \mathrm{J} /$. These are variably represented orthographically as é or $\dot{e}$, and $\dot{o}$ or $\dot{o}$, respectively. Because they are lower than the vowels represented by the symbols without the diacritic, the forms $\dot{e}$ and $o$ are adopted here. 
(26)
a. Ade [zitin-e jar]? who? name-N1/2SG.PSSR 3PL 'What are their names?'
c. tam-e za
father-N1/2SG.PSSR $3 \mathrm{SG}$
'his father'
b. Ade [zitin-e vur zèt]? who? name-N $1 / 2$ SG.PSSR river DEM 'What is the name of this river?'

With the lexical item tam 'father', the N1/2SG.PSSR suffix is attested as omitted in non$3 \mathrm{SG}$ contexts in two of the 12 recorded tokens, one of which is the only attested token in natural speech as opposed to elicitation (27b). This is optional deletion, and not an issue relating to the size of the possessor NP in (27b), as the other token of deletion, (27c), occurs in the same elicitation session as (27a) in a context structurally identical to (27a). It is perhaps significant that this deletion is attested only with the root tam 'father', as the 1SG form is suppletive and lacks any suffix, as in (27d). ${ }^{14}$
a. tam-e jar zar father-N1/2SG.PSSR 3PL 3PL 'their father'
c. tam dòr zituru father 1INCL.DU 1INCL.DU 'our (dual incl.) father'
d. mam ra father.1SG.PSSR 1SG 'my father'
b. tam jar zar sua-ro father 3PL 3PL child-PL 'the children's father'

Ririo is perhaps best known for its pervasive metathesis in which the final CVs of most roots have been transposed (Laycock 1982). This process also applies to pronouns, and to the 1SG.PSSR and 2SG.PSSR suffixes. Instead of the suffixes - $q u$ and - $m u$ found elsewhere in Choiseul, the Ririo forms reflect POC*-gu and *-mu with the CV metathesized, as in (28a,b).

$$
\begin{aligned}
& \text { a. körös-uq } \\
& \text { arm-1SG.PSSR } \\
& \text { 'my arm' }
\end{aligned}
$$

$$
\begin{aligned}
& \text { b. körös-um } \\
& \text { arm-2SG.PSSR } \\
& \text { 'your arm' }
\end{aligned}
$$
c. körös-e arm-N1/2SG.PSSR 'his/her arm'

The full details of Ririo metathesis (see Laycock 1982) are not relevant to the present discussion, and are reviewed in more detail by Palmer and Logan (n.d.). In summary, the operation of metathesis is conditioned by the vowel of the preceding syllable. Where the penultimate and final vowels form a falling sequence of high to nonhigh, metathesis has not occurred. In all other contexts, metathesis has occurred, bringing the penultimate and final vowels into adjacency and making the root consonant final (that is, ${ }^{*} V_{i} C V_{j} \rightarrow V_{i} V_{j} C$ ). Where the two resulting adjacent vowels have the same melody, one deletes, leaving a single vowel with that melody. Where they form a raising sequence from low (that is, /a) to nonlow, they coalesce to form a single vowel intermediate between $/ \mathrm{a} /$ and the mid-high or high final vowel. That intermediate vowel is the low mid vowel sharing the same front/

14. Although the 1SG form presumably derives historically from an address term, it forms a suppletive member of the paradigm of tam in synchronic Ririo. The form tam does not occur with a possessor suffix for 1SG (that is, the expected form *tam-uq does not occur). 
back feature as the original second vowel (thus $/ \mathrm{au} / \rightarrow / \mathrm{o} /, \mathrm{ae} / \rightarrow / \varepsilon /$, and so on). A number of other more fine-grained changes are also evident, including raising of mid high vowels in the penult, and loss of $/ \mathrm{v} /$ and $/ \mathrm{\gamma} /$ in final position after metathesis, among others. For the purposes of the present discussion, the crucial fact is that as a result of metathesis most, but not all, roots are consonant-final.

Following consonant-final roots, the 1SG and 2SG suffixes appear with their CV


to keep the consonant of the suffix separate from that of the root, and prevent the formation of word-internal codas. The situation is made superficially more complex by the occasional appearance of $/ \mathrm{u} /$ following the consonant in this context, as in (29). However, here the final $/ \mathrm{u} /$ is an echo vowel, not a reflex of the original final vowel. In Ririo, all words ending in a consonant take an optional echo vowel (Laycock 1982:274). In natural text, this is extensively attested with unsuffixed roots of various types, such as the dependent pronoun in (30), where there can be no question of the vowel being underlying (it derives through final $\mathrm{CV}$ metathesis from *ziru). Trivially, the echo vowel phenomenon also occurs with nouns displaying the suffixes - $u q$ and -um. A number of other complications exist that are not relevant to the issues at stake here. For a fuller analysis of the 1SG and 2SG suffixes, see Palmer and Logan (n.d.).

$$
\begin{aligned}
& \begin{array}{l}
\text { a. zitin-uq(u) } \\
\text { name-1SG.PSSR } \\
\text { 'my name' }
\end{array} \\
& \text { (30) jiur(u) } \\
& \text { 2DU } \\
& \text { 'you two' }
\end{aligned}
$$

With the non-1/2SG suffix, the underlying form in Ririo is $-e$. As indicated above, the effect of metathesis in the language means that most roots are consonant-final. When concatenated to these roots, the suffix has the form $-e$ and concatenates without any further modification of suffix or root, as in (26), (27a), (28c), and (29c).

The principles governing the operation of metathesis in the language mean that, with the exception of underlyingly monosyllabic roots (where metathesis does not operate), the only vowels to escape metathesis and be preserved in root-final position are /e/, /o/, and $/ \mathrm{a} /$, along with $/ \mathrm{o} /(o)$ in metathesized forms ending in $/ \mathrm{av} /$ where the final $/ \mathrm{v} /$ has been lost..$^{15}$ Moreover, these are only preserved in that position when the vowel of the preceding syllable is $/ \mathrm{u} /$ or $/ \mathrm{i} /$. This means that the number of attested roots with final vowels is small. Moreover, only a small subset of those are nouns that may carry direct possessor-indexing. The exception to these principles is underlyingly monosyllabic roots, which do not undergo metathesis. However, these are extremely few in number, and only two such roots are attested with direct possessor-indexing. The number of attested roots providing evidence on the behavior of the possessor suffixes when following vowels is, therefore, limited. However, the data are sufficient to observe patterns.

15. Final $/ \mathrm{v} /$ is regularly lost after metathesis in Ririo. However, if the preceding vowel is $/ \mathrm{a} /$, it is raised to $/ \mathrm{o} /(\dot{o})$ before $/ \mathrm{v} /$ is lost (Laycock 1982:275). For example, sò 'feather' is regularly derived as follows: *sava $\rightarrow$ *saav $\rightarrow *$ sav $\rightarrow *$ sòv $\rightarrow$ sò. 
No data exist in which a root with final /e/ carries direct possessor-indexing. On the basis of the apparently robust Ririo principle in which a sequence of two identical underlying vowels results in loss of one of those vowels (Laycock 1982:274-76), it is predicted that concatenation of the suffix $-e$ to a root with final /e/ would result in loss of the rootfinal /e/, resembling Babatana, as in (10f). However, the absence of data makes testing that hypothesis impossible. It is also impossible to rule out the presence following $/ \mathrm{e} / \mathrm{of}$ a disambiguating suffix allomorph $-a$, resembling Sisiqa in (23), as an allomorph $-a$ is attested in Ririo with only one root, as in (35c).

When following the vowel $/ \mathrm{o} / \mathrm{or} / \mathrm{J} /$, the suffix concatenates without modification of either the suffix or the root, as in (31).

$$
\begin{aligned}
& \text { a. mamno-e to' papad } \\
& \text { end-N1/2SG.PSSR LMT story } \\
& \text { 'the end of the story' }
\end{aligned}
$$

b. sò-e feather-N1/2SG.PSSR 'its feather'

When concatenated to a root ending in $/ \mathrm{a}$, the root-final vowel deletes, leaving the suffix, as in (32). In (32a), metathesis of the suffix CV brings the initial / $\mathrm{u} /$ of the suffix into adjacency with the root-final $/ \mathrm{a}$, resulting in the sequence /au/, which undergoes regular coalescence as $/ \mathrm{J} /(o)$, as shown in (33). This does not happen with the 2sG form in (32b) and (27e) above, because a separate process deletes the final $/ \mathrm{u} /$ of the $2 \mathrm{SG}$ suffix prior to metathesis in certain contexts, of which this is one. ${ }^{16}$ In this context, the suffix is reduced to $/ \mathrm{m} /$ prior to concatenation with the root, with the root-final $/ \mathrm{a} /$ intact.
a. sopòq belly.1SG.PSSR
'my belly' 'your belly'
c. sop-e belly-N1/2SG.PSSR 'his/her belly'
*sopa-qu $\rightarrow$ *sopa-uq $\rightarrow$ sopòq

Only two roots with high vowels are attested with direct possessor-indexing. These are the monosyllabic roots kü- 'younger same sex sibling' and ci- 'child of'. With kü-, the $\mathrm{N} 1 / 2$ SG.PSSR suffix occurs as $/ \mathrm{i} /$, as in (34), demonstrating the same raising height harmony seen in Babatana. With $c i$-, the vowel $/ \mathrm{i} /$ occurs in the root, and here the suffix occurs with the only attested instance of the allomorph $-a$ in Ririo, as in (35); compare this with the differently irregular cognate in Babatana in (16). The fact that this suffix form represents $\mathrm{N} 1 / 2 \mathrm{SG}$ as with $-e$, and is not an irregular use of a $3 \mathrm{SG}$ form, is demonstrated in (35d). This root is the only attested instance of a N1/2SG.PSSR allomorph $-a$ in Ririo. However, given that height harmony of the suffix occurs in (34), similar harmony with $c i$ - would result in a sequence /ii/. The - $a$ may, therefore, be a disambiguating lexical allomorph $-a$ following /i/, resembling $-a$ following /e/ in Babatana. However, the Babatana allomorph $-a$ does not also occur following $/ \mathrm{i} /$, and the situation with roots ending in /e/ in Ririo is unknown.

(34) kü-i

younger.same.sex.sib-N1/2SG.PSSR

'his/her younger same sex sibling' 
(35)
a. ci-uq
child-1SG.PSSR
'my child'
d. ci-a
child-N1/2SG.PSSR
b. ci-um
child-2SG.PSSR
'your child'
dòr
'our (two) child'

\author{
c. ci-a \\ child-N1/2SG.PSSR \\ 'his/her child'
}

In summary, the underlying form of the suffix in Ririo is /e/, with height assimilating raising to /i/ after high vowels, and with the disambiguating allomorph /a/ following /i/. Lack of data means it is not known whether the disambiguating allomorph /a/ also occurs following /e/. The synchronic Ririo situation is consistent with an originating form $*_{\mathrm{a}}$ retained only in the disambiguating context following /i/, or with an originating form *e with disambiguating lowering to /a/ (as with Babatana, /a/ is the only low vowel, so disambiguating lowering would necessarily result in /a/).

6. CONCLUSION. All three languages discussed here display an innovated possessor-indexing category non-1/2SG, with an innovated suffix encoding it. This suffix licenses a separate dependent pronoun or lexical NP expressing the possessor. In the absence of an overt possessor NP (lexical or pronominal), the suffix has a default 3SG reading.

The suffix itself displays the allomorphs /e/ or /a/, with an allomorph /i/ following high vowels in Babatana and Ririo. The suffix may have as its source the POC personal article $*$ i, with some Western Oceanic languages displaying reflexes of a protoform $*_{\mathrm{e}}$ in some contexts (Lynch, Ross, and Crowley 2002:71). Given that the suffix occurs frequently with dependent pronouns, this would be consistent with the presence of reflexes of $*$ e before pronouns in some other Northwest Solomonic languages. Alternative possible sources for the suffix may be the POC article *a (Crowley 1985; Lynch, Ross, and Crowley 2002:71), or the POC 3SG pronoun *ia (Malcolm Ross, pers. comm.) The synchronic situation in Babatana and Sisiqa is most consistent with an originating form *e, while the situation in Ririo is consistent with either originating *e or *a. Beyond these observations, no conclusions are drawn here about the historical origin of the suffix.

\section{REFERENCES}

Anderson, Stephen R. 2005. Aspects of the theory of clitics. Oxford: Oxford University Press.

Craven, Anna. 1977. [Audio recording of Ririo speaker Isaiah Poloso.]

Crowley, Terry. 1985. Common noun phrase marking in Proto-Oceanic. Oceanic Linguistics 24:135-93.

Hackman, Brian D. 1967. [Audio recording of Ririo speaker Isaiah Poloso.]

Laycock, Don. 1978. Ririo tape transcript. Typescript.

. 1982. Metathesis in Austronesian: Ririo and other cases. In Papers from the Third International Conference on Austronesian Linguistics, vol. 1: Currents in Oceanic, ed. by Amran Halim, Lois Carrington, and S. A. Wurm, 269-81. Canberra: Pacific Linguistics. 
Lichtenberk, Frantisek. 1983. Relational classifiers. Lingua 60:147-76.

Logan, Stephen. n.d. [Ririo fieldnotes.]

Lynch, John, Malcolm Ross, and Terry Crowley. eds. 2002. The Oceanic languages. Richmond, Surrey: Curzon Press.

McClatchey, Will. 2007. Babatana-English dictionary. MS.

Money, Lucy. 2002. Babatana grammar lessons. MS [edited by Piet Lincoln].

Palmer, Bill, and Dunstan Brown. 2007. Heads in Oceanic indirect possession. Oceanic Linguistics 46:199-209.

Palmer, Bill, and Stephen Logan. n.d. Dependent pronouns in Ririo. MS in preparation.

Ross, Malcolm. 1988. Proto Oceanic and the Austronesian languages of western Melanesia. Canberra: Pacific Linguistics.

- 2002. Sisiqa. In The Oceanic languages, ed. by John Lynch, Malcolm Ross, and Terry Crowley, 456-66. Richmond, Surrey: Curzon Press.

. n.d. [Questionnaire, Sisingga.]

Tryon, Darrell T., and Brian D. Hackman. 1983. Solomon Islands languages: An internal classification. Canberra: Pacific Linguistics.

Whaley, Owen G. 1962. Babatana segmental phonemes. Te Reo 5:60-62. 